\title{
Article
}

\section{Pharmacokinetics, metabolism and excretion of celecoxib, a selective cyclooxygenase-2 inhibitor, in horses}

Subhahar, Michael Benedict, Singh, Jaipaul, Albert, Peter Henry and Kadry, Ahmed Mahmoud

Available at http://clok.uclan.ac.uk/27747/

Subhahar, Michael Benedict, Singh, Jaipaul ORCID: 0000-0002-3200-3949, Albert, Peter Henry and Kadry, Ahmed Mahmoud (2019) Pharmacokinetics, metabolism and excretion of celecoxib, a selective cyclooxygenase-2 inhibitor, in horses. Journal of Veterinary Pharmacology and Therapeutics, 42 (5). pp. 518-524. ISSN 0140-7783

It is advisable to refer to the publisher's version if you intend to cite from the work. http://dx.doi.org/10.1111/jvp.12757

For more information about UCLan's research in this area go to http://www.uclan.ac.uk/researchgroups/ and search for <name of research Group>.

For information about Research generally at UCLan please go to http://www.uclan.ac.uk/research/

All outputs in CLoK are protected by Intellectual Property Rights law, including Copyright law. Copyright, IPR and Moral Rights for the works on this site are retained by the individual authors and/or other copyright owners. Terms and conditions for use of this material are defined in the policies page.

\section{CLoK}

Central Lancashire online Knowledge www.clok.uclan.ac.uk

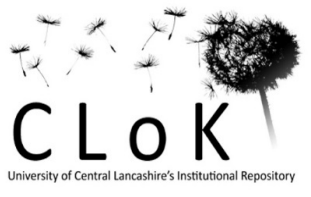




\section{$1 \quad$ Pharmacokinetic Report}

2

3 Pharmacokinetics, metabolism and excretion of celecoxib, a selective cyclooxygenase-2

4 inhibitor, in horses

5

$6 \quad$ M.B. Subhahar ${ }^{1}$, J. Singh ${ }^{2}$, P.H. Albert ${ }^{1}$, A.M. Kadry, ${ }^{1 *}$

7

$8{ }^{1}$ Equine Forensic Unit, Central Veterinary Research Laboratory, $2^{\text {nd }}$ Zabeel St, P.O. Box 597,

9 Dubai, UAE.

10

$11{ }^{2}$ School of Pharmacy and Biomedical Science and School of Forensic and Investigative

12 Sciences, University of Central Lancashire, Preston, U.K.

13

14

15

$16 *$ Correspondence:

$17 \quad$ A.M. Kadry

18 Equine Forensic Unit

19 Central Veterinary Research Laboratory

20 P.O.Box.597, Dubai, U.A.E.

21 E-mail address: akadry@cfldubai.ae

22 
Abstract

Celecoxib, a nonsteroidal anti-inflammatory drug is frequently used to treat arthritis in humans with minimal gastrointestinal side effect compared to traditional NSAIDs. The primary aim of this study is to determine the pharmacokinetic profile of celecoxib - a selective cyclooxygenase-2 (COX-2) inhibitor in horses. Six horses were administered a single oral dose of celecoxib at $2 \mathrm{mg} / \mathrm{kg}$ (body weight). After oral dosing, the drug reached a maximum concentration (mean $\pm \mathrm{SD}$ ) in blood of $1088 \pm 324 \mathrm{ng} / \mathrm{mL}$ in $4.58 \mathrm{~h}$. The elimination half-life was $13.60 \pm 3.18 \mathrm{~h}$ and the area under the curve was $24142 \pm 1096$ ng.mL/h. The metabolism of celecoxib in horses was via a single oxidative pathway in which the methyl group of celecoxib is oxidised to a hydroxymethyl metabolite and is further oxidised to form a carboxylic acid metabolite. Celecoxib is eliminated mainly through faeces as unchanged drug and as metabolites in urine. Therefore, instructions for a detection time following therapeutic dosing of celecoxib can be set by the racing practitioner and veterinarians to control illegal use in horse racing based on the results of this study.

39 Keywords: Celecoxib; Elimination; Horses; Metabolism; Pharmacokinetics. 
Celecoxib (4-[5-(4-methylphenyl)-3-(trifluoromethyl)-1H-pyrazol-1-yl]

benzenesulfonamide is the first COX-2 inhibitor to be developed as an analgesic with less toxicity on the gastrointestinal tract (Noble et al., 2000). Despite celecoxib has been clinically proven to be effective as a therapy for many species of animals (Zhang et al., 2000; Paulson et al., 2001; Störmer et al., 2003; Ma et al., 2015) there is limited data reported in horses although being banned as doping agent by horse racing authorities (The International Federation for Equestrian Sports, n.d.). A GC/MS method using TMS derivatization and an LC/MS study have been reported to characterize the metabolites of celecoxib in horse urine (Dirikolu et al., 2001; De Kock et al., 2005). However, the urine samples were collected for a short duration and a clear determination of detection time could not be established in their reports. Further, no detailed study to show data for the drug pharmacokinetics and detection time in horses is available. As such, this study was designated to characterise the plasma pharmacokinetics, metabolism pathways and elimination route of celecoxib given orally to horses, which assess the clinical and animal welfare implications and derive regulatory advice for horse racing industry.

\section{Materials and methods}

Animals

Six adult horses (males, male castrates and females) aged 12 to 18 years and weighing approximately $480 \mathrm{~kg}$ were used in the study. All animals were tagged, dewormed and housed in air-conditioned stable barns. The horses were given regular walking exercise for 30 minutes twice a day. Regular physical examination was performed on each horse by the local hospital veterinarian working adjacent to this facility. The animals were fed twice a day with hay, alfalfa and grains. They had free access to water. None of the horses had any disease 
history in their stable records and they were not treated with NSAIDs or other anti-

inflammatory drugs for at least 30 days prior to this administration study. The animals were fasted overnight prior to treatment and food was supplied after 2 hours of the first blood sample collected after drug administration. The study was approved by the Animal Ethics Committee of the Central Veterinary Research Laboratory in Dubai, U.A.E.

\section{Experimental chemicals}

Celecoxib and zaleplon were kind donations by Ipca Laboratories Limited, Indore, India, both having an assay purity of $\approx 99.8 \%$. $\beta$-glucuronidase from Helix pomatia (type HP2) and NADPH were purchased from Sigma Chemical Co. Ltd.. Hydroxymethyl celecoxib and celecoxib carboxylic acid were obtained from Alsachim (France). All organic solvents were either HPLC grade or LC/MS grade and purchased from Fisher Scientific. Horse liver microsomes were bought from Xeno Tech U.S.A for in vitro studies.

\section{Treatment and sample collection}

The study involved administration of a single oral solution dose of celecoxib at 2 $\mathrm{mg} / \mathrm{kg}$ body weight (bwt) to six horses using a naso-gastric tube. The administration was done in the presence of a clinical veterinary doctor. The drug was mixed with $250 \mathrm{~mL}$ of drinking water and poured into the tube using a funnel. The funnel was rinsed with another $100 \mathrm{~mL}$ of drinking water to ensure complete delivery of the drug into the horse stomach. Prior to drug administration an 18-guage catheter was placed either into the right or left jugular vein for the collection of blood samples. Blood samples were collected into heparinised tubes at $0,5,10$, 15, 30, 45 minutes and at 1, 2, 4, 8, 12, 24, 48, 72, 96, 120, 144, 168 and 192 hours post medication. The samples were immediately centrifuged, plasma separated and kept frozen at $20^{\circ} \mathrm{C}$ until use for drug analysis. A custom made diaper was tied to the animal for the 
collection of urine and faeces. Urine and faeces samples were collected whenever the animal disposed for seven days after administration and were pooled into morning and evening urine and faeces composites and stored at $-20^{\circ} \mathrm{C}$ until used for drug analysis.

\section{Plasma sample analysis}

Plasma samples were analysed by use of liquid chromatography- mass spectrometry (LC/MS). A previously validated solid phase extraction (SPE) method was carried out using automated extraction modules (RapidTrace, Biotage) and Waters SepPak C18 cartridge was used for the determination of celecoxib. Briefly, the C18 cartridge was sequentially conditioned with $3 \mathrm{~mL}$ of methanol and $0.1 \mathrm{M} \mathrm{KH} 2 \mathrm{PO} 4$ ( $\mathrm{pH} 6.0$ ). A volume of $1 \mathrm{~mL}$ plasma was allowed to pass through the column. Then the column was rinsed sequentially with $1 \mathrm{~mL}$ $0.1 \mathrm{M} \mathrm{KH} 2 \mathrm{PO} 4$ : methanol (90:10) and $1 \mathrm{~mL}$ of $1.0 \mathrm{M}$ acetic acid. Following drying for 2 minutes, the drug and its metabolites were eluted with $4 \mathrm{~mL}$ dichloromethane. The organic solvent was dried under a gentle flow of nitrogen on a TurboVap (Biotage) at $40{ }^{\circ} \mathrm{C}$. The residue was reconstituted in $50 \mu \mathrm{L}$ of mobile phase. In addition to administration samples, quality control samples with the drug spiked at different concentrations $(1,10,100,500$ and $1000 \mathrm{ng} / \mathrm{mL}$ ) were also assayed with each set.

A stock standard was prepared by dissolving $1 \mathrm{mg}$ of celecoxib in $100 \mathrm{~mL}$ of acetonitrile. The stock standard was further diluted by serial dilution to prepare standard solutions of 1,100 and $500 \mathrm{ng} / \mathrm{mL}$. Similarly $1 \mathrm{mg}$ of zaleplon was dissolved in $100 \mathrm{~mL}$ of methanol. This was further diluted to $1 \mu \mathrm{g} / \mathrm{mL}$ and used as internal standard. Calibration standards ranged from 1 to $1000 \mathrm{ng} / \mathrm{mL}$ were prepared by adding appropriate volumes of the standard drug solutions to drug free plasma. Zaleplon was used as the internal standard. A volume of $200 \mu \mathrm{L}(1 \mu \mathrm{g} / \mathrm{mL})$ of the internal standard was added to the calibration and test sample and extracted as mentioned above. 
115 The LC/MS system consisted of a Surveyor LC pump and auto sampler (Thermo Finnigan)

116 connected to a TSQ Access (Thermo Finnigan) mass spectrometer. Chromatographic

117 separation was performed using a Thermo Hypersil C18 column (100 x $2.1 \mathrm{~mm}$ ID., $5 \mu \mathrm{m}$

118 particle size) using a mobile phase consisting of acetonitrile and $1 \%$ formic acid in water, run

119 in a gradient mode. The mass spectrometer was operated in the negative ion mode performing

120 product ion scans $(\mathrm{m} / \mathrm{z} 380 \rightarrow 316),(\mathrm{m} / \mathrm{z} 396 \rightarrow 302)$ and $(\mathrm{m} / \mathrm{z} 410 \rightarrow 366)$ for celecoxib,

121 hydroxymethyl celecoxib and celecoxib carboxylic acid, respectively. Zaleplon=was scanned

122 in the positive ion mode for the transition $(\mathrm{m} / \mathrm{z} 306 \rightarrow 264)$.

123 The present study was able to examine the pharmacokinetics and characterize the metabolic

124 disposition of celecoxib after a single oral dose to horses, applying the proposed highly

125 selective and sensitive LC/MS with a limit of quantitation (LOQ) of $1 \mathrm{ng} / \mathrm{mL}$ and a limit of

126 detection (LOD) of $500 \mathrm{pg} / \mathrm{mL}$. No interfering peaks for celecoxib were observed in the

127 chromatograms of blank plasma from the horses used in the study. The intra-day and inter-day

128 assay precision and accuracy for low, medium and high $(10,100,200 \mathrm{ng} / \mathrm{mL})$ concentration

129 of celecoxib in horse plasma showed a coefficient of variation percentage (CV\%) ranging

130 from 5.6 to 9.8 and 4.9 to 8.0 , respectively.

Pharmacokinetic analysis

Pharmacokinetic parameters were determined for each animal individually utilizing

application of the trapezoidal rule for measurements of plasma drug concentration versus time

136 curve to achieve the non-compartmental methodology (Gibaldi \& Perrier, 1982; Martinez,

137 1998; Gabrielsson \& Weiner, 2012) using a computerized pharmacokinetic and drug

138 disposition program (Kinetica Version 5.1 SP1, Thermo). For each parameter, the mean and

139 standard deviation (SD) were obtained from the calculation results of six animals $(n=6)$. 
140 In order to estimate the celecoxib dose for horses from an efficacious dose in human, the

141 following equation was applied (Toutain \& Bousquet-Mélou, 2004):

$$
\text { Dose }_{\text {horse }}=\frac{\text { Dose }_{\text {human }} \times C L_{\text {horse }}}{C L_{\text {human }}}
$$

143 In addition, determinations of an effective plasma concentration (EPC), irrelevant plasma

144 concentration (IPC), safety factor (SF) and detection time (DT) were based on the following 145 equations (Toutain \& Lassourd, 2002):

$$
\begin{aligned}
& E P C=\frac{\text { standard dose }(\text { per dosing interval })}{\text { plasma clearance }(\text { per dosing interval })} \\
& I P C=\frac{E P C}{S F} \\
& I P C=C_{\text {max }} \times e^{(-\beta \times D T)}
\end{aligned}
$$

Determination of metabolites 192 hours after administration. An aliquot of $10 \mathrm{~mL}$ of each urine sample was adjusted to $\mathrm{pH}$ 5.2 and approximately 10,000 Fishman units of $\beta$-glucuronidase was added and incubated at $37^{\circ} \mathrm{C}$ overnight. Another aliquot of $10 \mathrm{~mL}$ urine was processed simultaneously without enzyme hydrolysis. Similarly an amount of 10 grams of faeces was weighed and mixed

156 thoroughly with $10 \mathrm{~mL}$ of distilled water. The slurry is then centrifuged at $4000 \mathrm{~g}$ for 15 minutes. A volume of $7 \mathrm{~mL}$ of this clear liquid was adjusted to $\mathrm{pH} 5.2$ and enzyme hydrolysed overnight at $37^{\circ} \mathrm{C}$.

159 The enzyme hydrolysed urine and faeces samples were adjusted to $\mathrm{pH} 6.0$ and again

160 centrifuged for 15 minutes. To $5 \mathrm{~mL}$ of each sample $200 \mu \mathrm{L}(1 \mu \mathrm{g} / \mathrm{mL})$ of internal standard

161 was added and subjected to solid phase extraction as described above. The final eluent was dried and reconstituted with $50 \mu \mathrm{L}$ of the mobile phase for LC/MS analysis. 


\section{In vitro metabolism of celecoxib}

To characterize the in vitro metabolic pathway, celecoxib was incubated with horse liver microsomes. In this study, all the incubations were performed in duplicates in a shaking water bath at $37^{\circ} \mathrm{C}$. The experimental protocol is as follows: To $5 \mu \mathrm{L}$ of celecoxib $(1 \mathrm{mM})$ is added $432 \mu \mathrm{L}$ of $0.1 \mathrm{M}$ sodium phosphate buffer $(\mathrm{pH} 7.4)$ and $13 \mu \mathrm{L}$ of the protein $(0.5$ $\mathrm{mg} / \mathrm{mL}$ ), premixed and allowed to stand at room temperature for 3 minutes. The incubation was commended by the addition of $10 \mathrm{mM}$ NADPH $(50 \mu \mathrm{L})$ and allowed to react for 30 minutes with constant gentle shaking. After incubation the reaction was quenched by addition of $100 \mu \mathrm{L}$ of ice cold methanol. The resulting mixture was then extracted with dichloromethane, centrifuged and the organic phase was dried and reconstituted with $50 \mu \mathrm{L}$ of the mobile phase for LC/MS analysis.

\section{Results}

The pharmacokinetic parameters of celecoxib after an oral dose of $2 \mathrm{mg} / \mathrm{kg}$ bwt are shown in Table 1. The results show that after oral administration of celecoxib the time to reach peak plasma concentration $\left(\mathrm{t}_{\max }\right)$ was $4.58 \pm 1.62$ hours and the rate of elimination was calculated to be $0.05 \pm 0.01 \mathrm{hr}^{-1}$, while the terminal half-life (t1/2) was estimated to be 13.60 \pm 3.18 hours. The mean \pm standard deviation plasma concentration-time profile of celecoxib following oral single dose administration to six horses is graphically presented in Figure 1.

Celecoxib was extensively metabolized after oral administration with low levels of the parent drug detected in urine for up to 72 hours. The majority of urinary metabolite consisted of carboxylic acid metabolite which was about $105.53 \mathrm{ng} / \mathrm{mL}$ and approximately $3 \mathrm{ng} / \mathrm{mL}$ of hydroxymethyl metabolite of celecoxib at 24 hours after oral administration. Moreover, this study shows that the carboxylic acid and hydroxymethyl metabolites of celecoxib could be 
detected in urine for 96 and 48 hours respectively. However, the parent drug and carboxylic

189 acid metabolite could be detected in faeces for 120 hours after administration (Figure 2). Further, the in vitro study using horse liver microsomes evidenced the formation of

191 only two metabolites for the parent drug and no other transformations could be detected using 192 a precursor ion/product ion scan by mass spectrometry (Figure 3).

Discussion

The use of a sensitive and specific analytical technique for the determination of celecoxib in biological samples is of paramount importance in pharmacokinetics study. High performance liquid chromatography with UV or fluorescence detection has been most widely used in the detection of celecoxib (Rose et al., 2000; Störmer et al., 2003; Zarghi et al., 2006).

199 A liquid chromatography-tandem mass spectrometric quantitation of celecoxib in human plasma and rat, employing solid phase extraction was developed by (Bräutigam et al., 2001). Presently mass spectrometry has been predominantly used in the pharmacokinetics and metabolic study of celecoxib (Zhang et al., 2000; Werner et al., 2002; Ma et al., 2015). The present pharmacokinetic data obtained from horses in this study when compared 204 to humans and other animals is more or less in complete agreement for celecoxib oral administration, irrespective of the species differences (Paulson et al., 2000a ; Paulson et al., 2001; Werner et al., 2002; Itthipanichpong et al., 2005; Park et al., 2012). However, in this study the plotted plasma concentration-time profile shows that there was a rapid increase in 208 celecoxib level in about four hours and then the level decreases gradually reaching detectable 209 levels up to approximately 96 hours following administration (Figure 1). Moreover, the large volume of distribution $(\mathrm{Vd} / \mathrm{F})$ and the slow elimination recorded in this study are suggesting

211 extensive distribution of the drug and / or a poor bioavailability in the body of horses. 
In the present study, the dosing of $2 \mathrm{mg} / \mathrm{kg}$ bwt was based on applying of more or less the same dose as reported for celecoxib urinary metabolism in horse (Dirikolu et al., 2001; De Kock et al., 2005), along with the assumption of equal efficacious plasma concentration between human and horse due to lack of experimental data; and unavailability of celecoxib pharmaceutical preparation in the veterinary market for horses. However, the found plasma clearance in this study $(\mathrm{CL} / \mathrm{F}=98.48 \mathrm{~mL} / \mathrm{kg} / \mathrm{h})$ can be of a starting guide to extrapolate a provisional dose from another species assuming that the same overall body exposure (AUC) will produce the same effect in both species (Toutain \& Bousquet-Mélou, 2004). Considering the extent of plasma binding is the same between humans and horses with equal bioavailability factor, F, celecoxib oral dose in horses can be extrapolated tentatively by applying equation (1); where the reported human plasma clearance (CL/F) for $3 \mathrm{mg} / \mathrm{kg}$ oral administration of celecoxib is $396 \mathrm{~mL} / \mathrm{kg} / \mathrm{h}$ (Brunton et al., 2018), the calculated dose for horses is about $0.75 \mathrm{mg} / \mathrm{kg}$. Consequently, the average plasma concentration that would be achieved in steady-state condition in horses with chronic dosing of $0.75 \mathrm{mg} / \mathrm{kg}$ per day is about $317 \mathrm{ng} / \mathrm{mL}$.

Experimental results of this study advise a detection time in horse plasma of approximately 5 days when celecoxib is administered at $2 \mathrm{mg} / \mathrm{kg}$ bwt based on the achieved analytical LOQ of $1 \mathrm{ng} / \mathrm{mL}$. This also was proven by the generic pharmacokinetic/pharmacodynamics approach (Toutain \& Lassourd, 2002) based on the determinations of EPC, IPC, SF and the found PK parameters allowing computing of the detection time (DT) by the equations 2, 3 and 4; where the standard dose in this study is $2 \mathrm{mg} / \mathrm{kg}$ and the found plasma clearance is $98.48 \mathrm{~mL} / \mathrm{kg} / \mathrm{h}$, the calculated EPC is $846.20 \mathrm{ng} / \mathrm{mL}$. Applying a default safety factor of 500 (Toutain \& Lassourd, 2002) will result in irrelevant plasma concentration of $1.70 \mathrm{ng} / \mathrm{mL}$. Where the slope of the terminal phase $(\beta)$ found in the present study is $0.05 \mathrm{~h}^{-1}$ and drug maximum concentration in plasma is $1088 \mathrm{ng} / \mathrm{mL}$, the 
computed DT is 5.4 days more or less. Given the above, attention should be given for the change of detection time with a change in celecoxib dose, typically when applying the extrapolated therapeutic dose computed with Eqn (1).

In humans, celecoxib has been found to be extensively metabolized in the liver with < $3 \%$ is excreted unchanged and the major route of elimination are faeces and urine (Davies et al., 2000). A reported in vitro study for celecoxib metabolism using allelic variant forms of 243 human liver microsomal cytochrome P450 2C9 evidenced the formation of three metabolites, 244 namely: hydroxylated celecoxib, carboxycelecoxib and its corresponding glucuronide (Tang 245 et al., 2001). In addition, it was reported that hydroxylation is the primary pathway of 246 elimination in humans and is similar in several species such as mouse, rat, rabbit, dog and 247 monkey while the carboxylic acid metabolite of celecoxib undergoes further glucuronidation 248 to form carboxylic acid glucuronide and is excreted in urine (Paulson et al., 2000b; Paulson et 249 al., 2001). However, an interesting observation is noticed on the elimination of celecoxib in 250 horses that the parent drug is excreted as the major component compared to a significantly 251 lower level of the carboxylic acid metabolite excreted in faeces (Figure 2). The high 252 concentration of celecoxib in the faeces could be the unabsorbed drug. The two major urinary 253 metabolites of celecoxib in horses were characterized and identified as 4-hydroxycelecoxib 254 and 4-carboxycelecoxib (Dirikolu et al., 2001; De Kock et al., 2005). Moreover, it has been 255 found that there was no appreciable change in the concentration of the carboxylic acid 256 metabolite when using either hydrolysed or unhydrolysed urine suggesting that the drug or its 257 metabolite is excreted without conjugation which is evidenced by the absence of any 258 glucuronic acid conjugate when using a neutral loss screen by LC/MS. Hence, the carboxylic 259 acid metabolite accounts for more than $90 \%$ and the parent drug accounts for $1-2 \%$ of the 260 elimination of celecoxib in horse urine. 
262 the possibility to increase artificially both the physical capability and the presence of a 263 competitive instinct, using drugs. However, an anti-doping policy must not impede the use of 264 legitimate therapeutic medications and most regulatory bodies in the world now distinguish 265 the control of illicit substances (doping control) from the control of therapeutic substances 266 (medication control) (Toutain, 2010). This study indicates that the detection of celecoxib and 267 its carboxy metabolite are key elements for celecoxib doping investigation in horses, due to 268 prolonged elimination profile and considerably high detection concentration in urine and 269 faeces. It is concluded that a detection time of at least 5 days is advised for racing practitioner 270 and veterinarians after administration of oral therapeutic dose of celecoxib at $2 \mathrm{mg} / \mathrm{kg}$ (body 271 weight) to control its illegitimate use for horse racing. Attention should be given for 272 computing the detection time upon administration of different oral dose.

\section{Acknowledgements}

The authors wish to thank the Veterinarian of the Dubai Equine Hospital in drug 276 administration and collection of blood samples.

\section{Conflict of interest statement}

The authors planned, designed and conducted this study. The authors declare no 280 conflict of interest.

\section{References}

284 Bräutigam, L., Vetter, G., Tegeder, I., Heinkele, G. \& Geisslinger, G. (2001). Determination of celecoxib in human plasma and rat microdialysis samples by liquid chromatography 
tandem mass spectrometry. Journal of Chromatography B, 761, 203-212.

Brunton, L.L., Knollmann, B.C. \& Hilal-Dandan, R. (2018). Goodman \& Gilman's

pharmacological basis of therapeutics (13 ${ }^{\text {th }}$ ed.). McGraw-Hill Medical, New York, NY.

Davies, N.M., McLachlan, A.J., Day, R.O. \& Williams, K.M. (2000). Clinical

pharmacokinetics and pharmacodynamics of celecoxib: a selective cyclo-oxygenase-2 inhibitor. Clinical Pharmacokinetics, 38, 225-242.

294

De Kock, S.S., Jogi, P. \& Boshoff, R. (2005). Mass spectrometric detection of rofecoxib and celecoxib and major metabolites in horse urine. In $15^{\text {th }}$ International Conference of Racing Analysts and Veterinarians. Eds Albert, P.H., Morton, T. \& Wade J.F. pp. 365-371. R \& W Publication Ltd, Dubai, UAE.

299

Dirikolu, L., Lehner, A.F., Jacobs, J., Woods, W.E., Karpiesiuk, W., Harkins, J.D., Carte,

W.G., Boyles, J., Hughes, C.G., Bosken, J.M., Holtz, C., Natrass, C., Fisher, M. \& Tobin T.

(2001). Celecoxib in the horse: its recovery, mass spectroscopic identification, disposition and major urinary metabolites. In $13^{\text {th }}$ International Conference of Racing Analysts and

Publication Ltd, Cambridge, UK.

Gabrielsson, J. \& Weiner, D. (2012). Non-compartmental analysis. Methods in Molecular 
York, pp. 45-108.

Itthipanichpong, C., Chompootaweep, S., Wittayalertpanya, S., Kemsri, W., Thaworn, N.,

314 Lilitkarntrakul, P. \& Parikamsil, S. (2005). Clinical pharmacokinetic of celecoxib in healthy

315 Thai volunteers. Journal of the Medical Association of Thailand, 88, 632-638.

Ma, Y., Gao, S. \& Hu, M. (2015). Quantitation of celecoxib and four of its metabolites in rat

blood by UPLC-MS/MS clarifies their blood distribution patterns and provides more accurate pharmacokinetics profiles. Journal of Chromatography B, 1001, 202-211.

Martinez, M.N. (1998). Non compartmental methods of drug characterization: statistical moment theory. Journal of the American Veterinary Medical Association, 213, 974-980.

Noble, S.L., King, D.S. \& Olutade, J.I. (2000). Cyclooxygenase-2 enzyme inhibitors: place in therapy. American Family Physician, 61, 3669-3676.

Park, C.W., Tung, N.T., Son, D.D., Kim, J.Y., Rhee, Y.S., Kang, S.Y., Park, S.A., Hwang, K.M., Oh, T.O., Ha, J.M., Chi, S.C. \& Park, E.P. (2012). Preparation and in vivo evaluation of immediate-release pellet containing celecoxib solid dispersion. Journal of Pharmaceutical Investigation, 42, 121-126.

331 Paulson, S.K., Vaughn, M.B., Jessen, S.M., Lawal, Y., Gresk, C.J., Yan, B., Maziasz, T.J.,

332 Cook, C.S. \& Karim, A. (2001). Pharmacokinetics of celecoxib after oral administration in dogs and humans: effect of food and site of absorption. Journal of Pharmacology and Experimental Therapeutics, 297, 638-645. 
Paulson, S.K., Zhang, J.Y., Breau, A.P., Hribar, J.D., Liu, N.W., Jessen, S.M., Lawal, Y.M.,

Cogburn, J.N., Gresk, C.J., Markos, C.S., Maziasz, T.J., Schoenhard, G.L. \& Burton, E.G.

(2000a). Pharmacokinetics, tissue distribution, metabolism, and excretion of celecoxib in rats.

Drug Metabolism and Disposition, 28, 514-521.

Paulson, S.K., Zhang, J.Y., Jessen, S.M., Lawal, Y., Liu, N.W., Dudkowski, C.M., Wang,

Y.F., Chang, M., Yang, D., Findlay, J.W., Berge, M.A., Markos, C.S., Breau, A.P., Hribar,

J.D. \& Yuan, J. (2000b). Comparison of celecoxib metabolism and excretion in mouse, rabbit, dog, cynomolgus monkey and rhesus monkey. Xenobiotica, 30, 731-744.

Rose, M.J., Woolf, E.J. \& Matuszewski, B.K. (2000). Determination of celecoxib in human plasma by normal-phase high-performance liquid chromatography with column switching and ultraviolet absorbance detection. Journal of Chromatography B, 738, 377-385.

Störmer, E., Bauer, S., Kirchheiner, J., Brockmöller, J. \& Roots, I. (2003). Simultaneous determination of celecoxib, hydroxycelecoxib, and carboxycelecoxib in human plasma using gradient reversed-phase liquid chromatography with ultraviolet absorbance detection. Journal of Chromatography B, 783, 207-212.

Tang, C., Shou, M., Rushmore, T.H., Mei, Q., Sandhu, P., Woolf, E.J., Rose, M.J., Gelmann, A., Greenberg, H.E., De Lepeleire, I., Van Hecken, A., De Schepper, P.J., Ebel, D.L., Schwartz, J.I. \& Rodrigues, A.D. (2001). In-vitro metabolism of celecoxib, a cyclooxygenase2 inhibitor, by allelic variant forms of human liver microsomal cytochrome P450 2C9: correlation with CYP2C9 genotype and in-vivo pharmacokinetics. Pharmacogenetics and

360 Genomics, 11, 223-235. 
362 The International Federation for Equestrian Sports (n.d.). The FEI equine prohibited

363 substances database. Retrieved from

364 http://prohibitedsubstancesdatabase.feicleansport.org/search

366 Toutain, P.L. \& Bousquet-Mélou, A. (2004). Plasma clearance. Journal of Veterinary

367 Pharmacology and Therapeutics, 27, 415-425.

Toutain, P.L. \& Lassourd, V. (2002). Pharmacokinetic/pharmacodynamic approach to assess

370 irrelevant plasma or urine drug concentrations in postcompetition samples for drug control in

371 the horse. Equine Veterinary Journal, 34, 242-249.

372

Toutain, P.L. (2010). Veterinary medicines and competition animals: the question of medication versus doping control. Handbook of Experimental Pharmacology, 199, 315-339.

376 Werner, U., Werner, D., Pahl, A., Mundkowski, R., Gillich, M. \& Brune, K. (2002).

377 Investigation of the pharmacokinetics of celecoxib by liquid chromatography-mass spectrometry. Biomedical Chromatography, 16, 56-60.

Zarghi, A., Shafaati, A., Foroutan, S.M. \& Khoddam ,A. (2006). Simple and rapid high-

381 performance liquid chromatographic method for determination of celecoxib in plasma using

382 UV detection: application in pharmacokinetic studies. Journal of Chromatography B, 835, 100-104. 
386 Breau, A.P. (2000). Characterization of metabolites of celecoxib in rabbits by liquid

387 chromatography/tandem mass spectrometry. Journal of Mass Spectrometry, 35, 1259-1270.

388 
390 Pharmacokinetic parameters of celecoxib in horses $(n=6)$ after a single oral solution

391 administration at a dose of $2 \mathrm{mg} / \mathrm{kg}$ (body weight). Values are presented as means \pm standard 392 deviation (SD).

\begin{tabular}{lc}
\hline Pharmacokinetic parameter & Mean $\pm \mathrm{SD}$ \\
\hline Drug maximum concentration in plasma $\left(\mathrm{C}_{\max }\right) \mathrm{ng} / \mathrm{mL}$ & $1088 \pm 324$ \\
Time to reach peak plasma concentration $\left(\mathrm{t}_{\mathrm{max}}\right) \mathrm{h}$ & $4.58 \pm 1.62$ \\
Rate of elimination $(\beta) \mathrm{h}^{-1}$ & $0.05 \pm 0.01$ \\
elimination half-life $\left(\mathrm{t}_{1 / 2 \beta}\right) \mathrm{h}$ & $13.60 \pm 3.18$ \\
Volume of distribution $(\mathrm{Vd} / \mathrm{F}) \mathrm{mL} / \mathrm{kg}$ & $1904.13 \pm 974.69$ \\
Clearance $(\mathrm{CL} / \mathrm{F}) \mathrm{mL} / \mathrm{h} / \mathrm{kg}$ & $98.48 \pm 48.16$ \\
& \\
AUC 0 -t $\mathrm{ng} . \mathrm{h} / \mathrm{mL}$ & $24142 \pm 1096$ \\
\hline
\end{tabular}




\section{Figure legends}

396 Figure 1: Time course changes (mean \pm SD) of plasma concentration of celecoxib following

397 oral administration of a single dose of $2 \mathrm{mg} / \mathrm{kg}$ body weight to 6 healthy horses.

398

399 Figure 2: Time course changes of faecal excretion of celecoxib and its metabolite COOH-

400 celecoxib.

401

402 Figure 3: LC-MS/MS extracted ion chromatogram and mass spectra of (A) celecoxib (RT = 6.65

$403 \mathrm{~min})$, (B) hydroxymethyl celecoxib metabolite $(\mathrm{RT}=6.10 \mathrm{~min})$ and $(\mathrm{C})$ celecoxib carboxylic acid

404 metabolite $(\mathrm{RT}=6.07)$ obtained from in vitro metabolism of celecoxib using horse liver mircorsomes.

405

406 Figure 1:

407

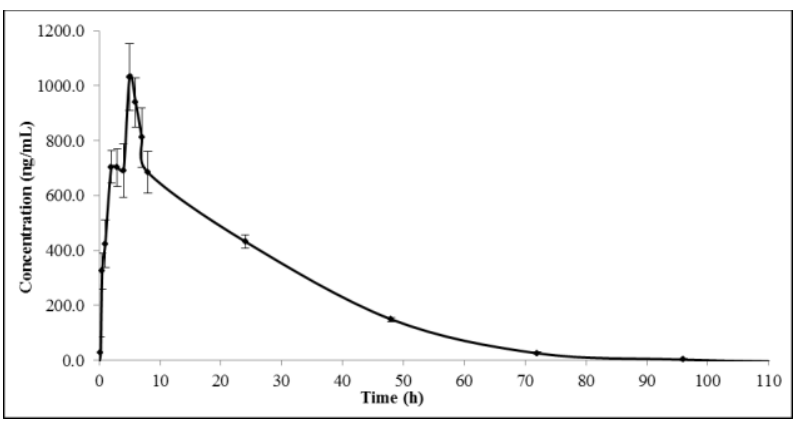

408

409

410

411

412

413

414

415 
416 Figure 2:

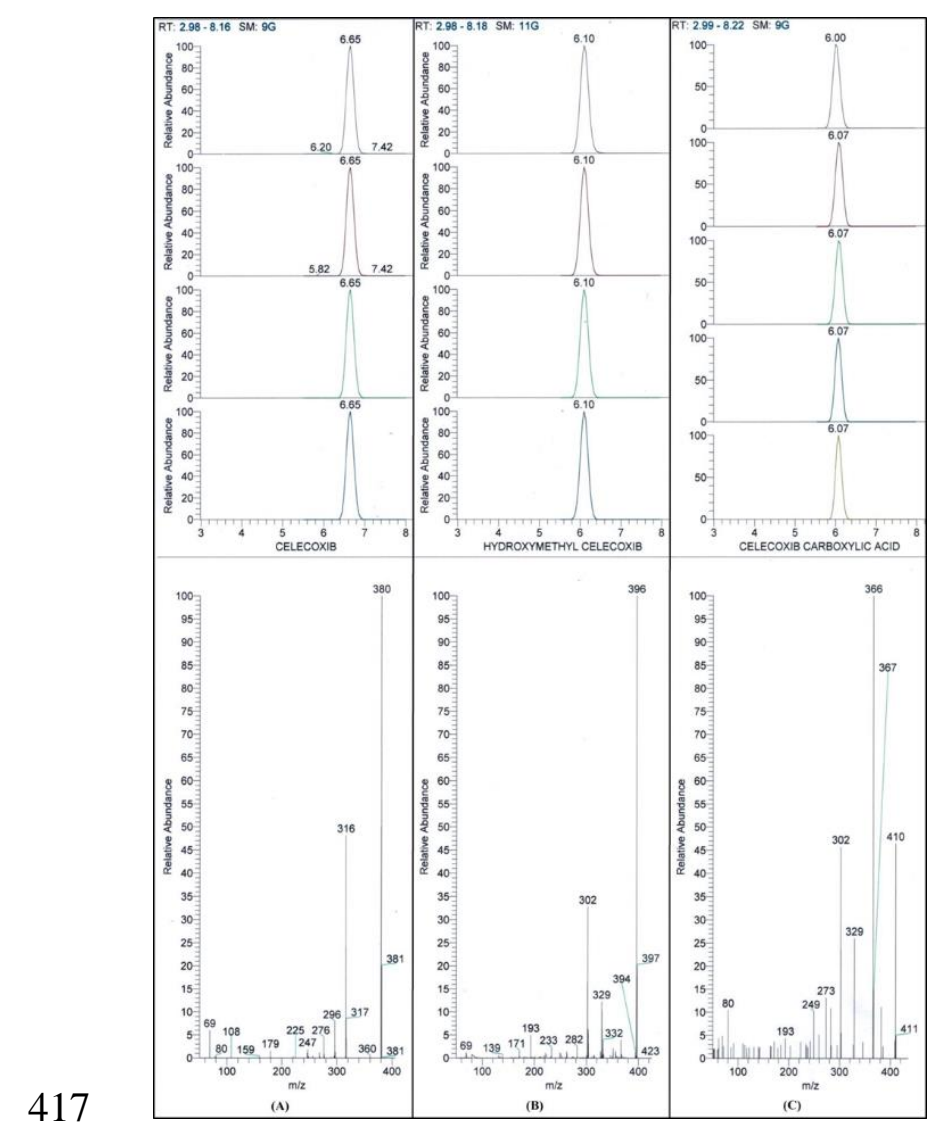

418

419 Figure 3:

420

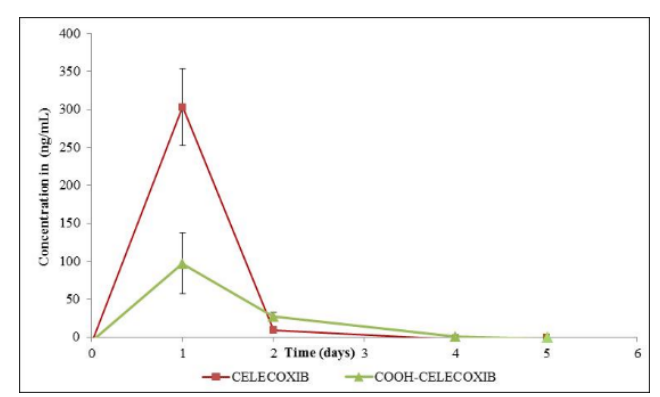

